\title{
IMPACT OF NOURISHMENTS ON NEARSHORE CURRENTS AND SWIMMER SAFETY ON THE DUTCH COAST
}

\author{
Roeland C. de Zeeuw ${ }^{1}$, Matthieu A. de Schipper ${ }^{1}$, Dano Roelvink ${ }^{2}$, Sierd de Vries ${ }^{1}$ and \\ Marcel J. F. Stive ${ }^{1}$
}

\begin{abstract}
Assessing swimmer safety along the Dutch coast entails more than only assessing the risk of rip currents. Seven criteria have been formulated to make a comprehensive assessment of swimmer safety along the Dutch coast. These are based on interviews with lifeguards, rescue report statistics and detailed lagrangian measurements of the current patterns and bathymetry in the shallow nearshore, at three different field sites along the South-Holland coast.
\end{abstract}

Keywords: swimmer safety, nourishments, longshore current, rip current, coastal structures, GPS drifters.

\section{INTRODUCTION}

Commonly beach safety is associated with rip currents (e.g. Dalrymple et al, 2011). On swell dominated coasts with large bathymetric variations in the nearshore and small longshore currents these rips can form a great risk for bathers. However, along the wind sea dominated Dutch coast with small vertical bathymetric variations, frequent nourishments and combined tidal, wind and wave driven alongshore currents reaching $1 \mathrm{~m} / \mathrm{s}$ or more, rips are found to be only one part of beach safety.

Assessing swimmer safety along the Dutch coast entails more than only assessing the risk of rip currents. Seven criteria have been formulated to make a comprehensive assessment of swimmer safety along the Dutch coast:

1. Bars, troughs and channels

2. Profile gradients

3. Coastal structures

4. Rip currents

5. Predictability

6. Longshore currents

7. Coastline gradients

These criteria resulted from lifeguard interviews, rescue report statistics and detailed lagrangian measurements of the currents and bathymetry in the shallow nearshore, at three different field sites along the South-Holland coast.

\section{Background}

The objective of the present study was to investigate the impact of nourishments on swimmer safety and to gain insight into relevant hydrodynamic and morphologic aspects of the Dutch coast with respect to swimmer safety. Motivation for this study was the concern of lifeguards and municipalities regarding swimmer safety on the newly nourished beaches. Over the last decades the size of beach and foreshore nourishments as executed widely along the Dutch coast, has increased from $0.7 \mathrm{Mm} 3 / \mathrm{km}$ to over $6 \mathrm{Mm} 3 / \mathrm{km}$. At several locations entire new dynamic coastlines are created by these nourishments. Groynes which were present along the southern Holland coast from the 19th century onwards are now (partly) covered with sand. This change to an entire new beach configuration causes uncertainty and concerns amongst swimmers, lifeguards and (local) governments regarding the nearshore current pattern and morphology, to which they had been used to for decades.

\section{FIELD SITES}

Three field sites were studied, all situated along the coast of South-Holland, the Netherlands. This $20 \mathrm{~km}$ long sandy stretch is located between the Rotterdam harbor and the Hague and notorious for its structural erosion. Close to the most densely populated part of the Netherlands, the stretch has ample lifeguard stations near the city of The Hague (HVRB Post 1 to 5) and the villages of Ter Heijde and 's Gravenzande (GVRB), see also Figure 1.

\footnotetext{
${ }^{1}$ Coastal Engineering, Section of Hydraulic engineering, Delft University of Technology, Delft, The Netherlands.

${ }^{2}$ UNESCO-IHE Institute for Water Education, Delft, The Netherlands
} 


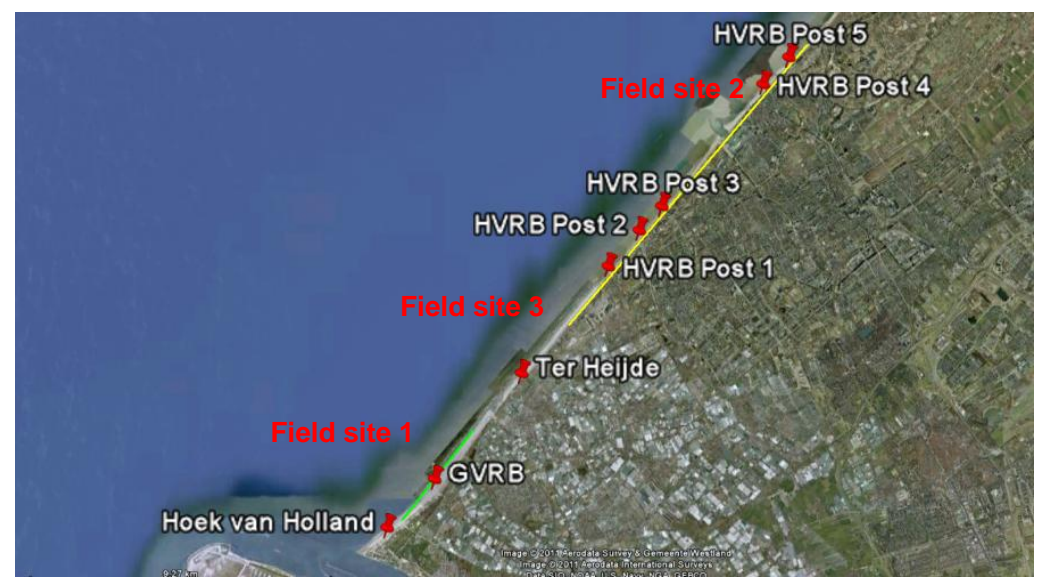

Figure 1. Location of field sites along the South Holland coast of the Netherlands. Lifeguard stations of The Hague (HVRB Post 1-5) and Vlugtenburg (GVRB) are indicated as well as the coastal village of Ter Heijde.

\section{Field site 1: Vlugtenburg}

Vlugtenburg beach was characterized by groynes until 2008. Extensive beach and forseshore nourishments in 2008 and 2009 created a new beach configuration. An entire new dune row and valley were constructed. Figure 2 shows the execution of the nourishment and the original dune, beach and coastline with groynes. Figure 3 shows the northern part of the construction, showing the groynes more clearly. After construction, the coastline was shifted several hundreds of meters seawards covering all groynes with sand.

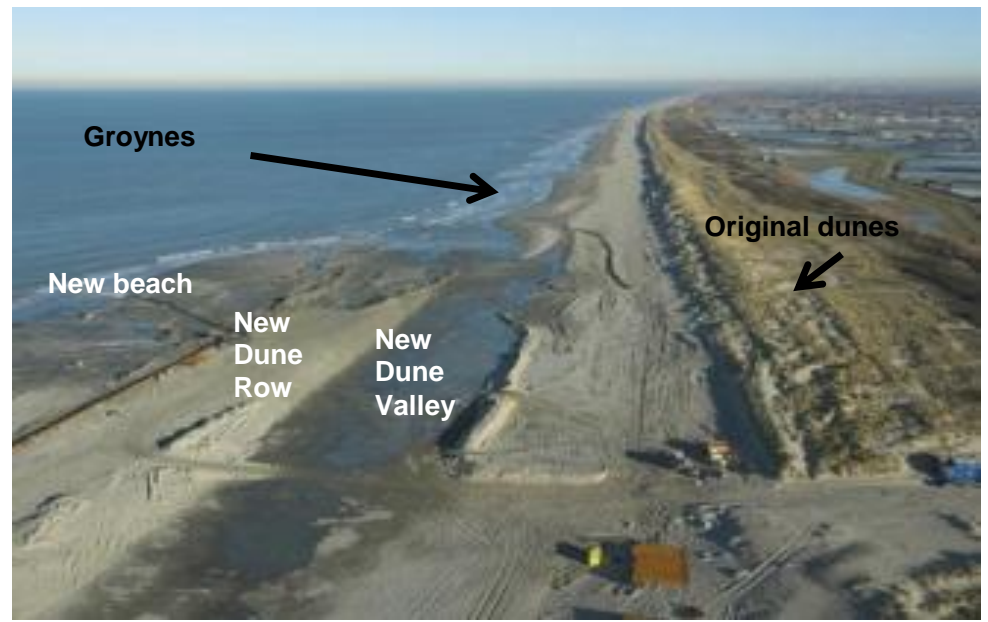

Figure 2: Aerial photograph of the Vlugtenburg fieldsite during construction of the nourishment in 2009. Original beach and vegetated dunes visible on the left. (source: www.delflandsekust.nl)

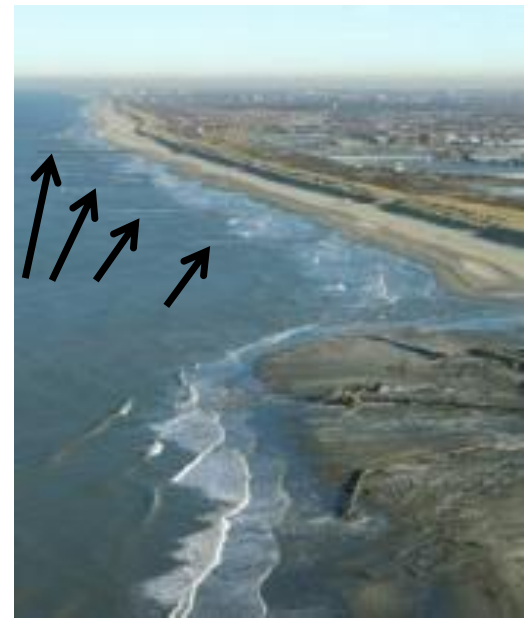

Figure 3: Aerial photograph of the northern end of the Vlugtenburg field site during construction. Groynes at the southern end are already covered with sand. (source: www.delflandsekust.nl) 


\section{Field site 2: Scheveningen}

Scheveningen beach is the main tourist beach of the city of the Hague, located just north of the harbour moles. Figures 4 and 5 show the beach of Scheveningen before and after the nourishment of 2010 respectively. The nourishment covered the groynes completely with sand. The alongshore (lateral) boundaries of the nourishment initially resulted in sharp alongshore gradients in the coastline.

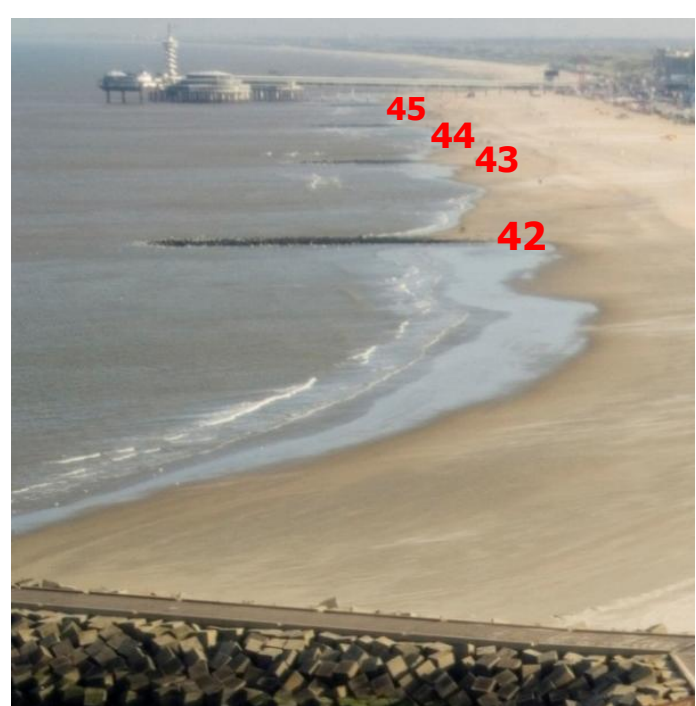

Figure 4: Beach of Scheveningen prior to the nourishment in 2009. Numbers correspond to individual groynes.

(source: www.kustfoto.nl)

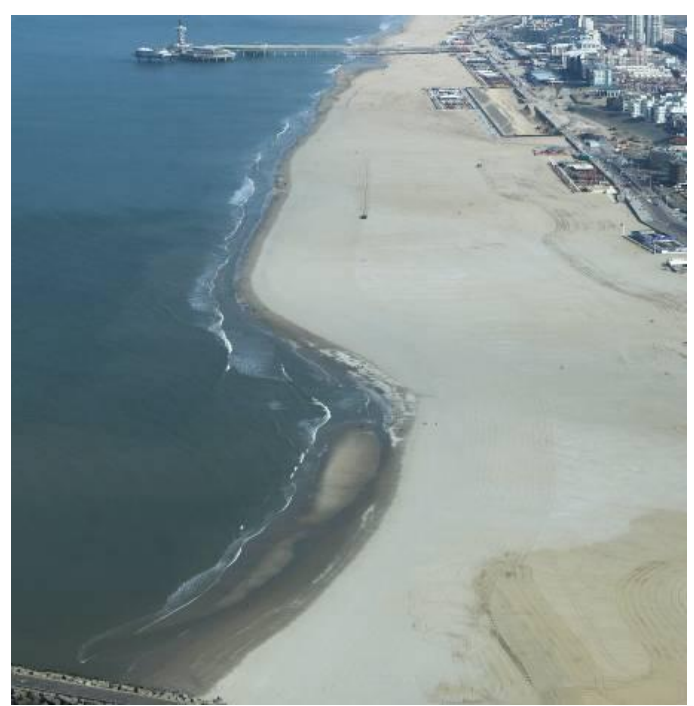

Figure 5: Nourished beach of Scheveningen in 2010. Groynes 42 to 44 are covered by the nourishment, 45 still present. (source: projectbureau Combinatie Delftlandse Kust)

\section{Field site 3: The Sandengine}

The third field site is the mega scale nourishment just north of Ter Heijde and south of The Hague (HVRB post 1), called the Sandengine (see Fig. 1). Approximately $19 \mathrm{Mm}^{3}$ sand has been nourished along a $2.5 \mathrm{~km}$ stretch of coast. The nourishment is designed as sediment supplier for the adjacent coast and provider of extra natural and recreational area. Like the other field sites, existing groynes were covered with sand as a result of the nourishment and an entirely new coastline and beach configuration was created (Figures 6 and 7).
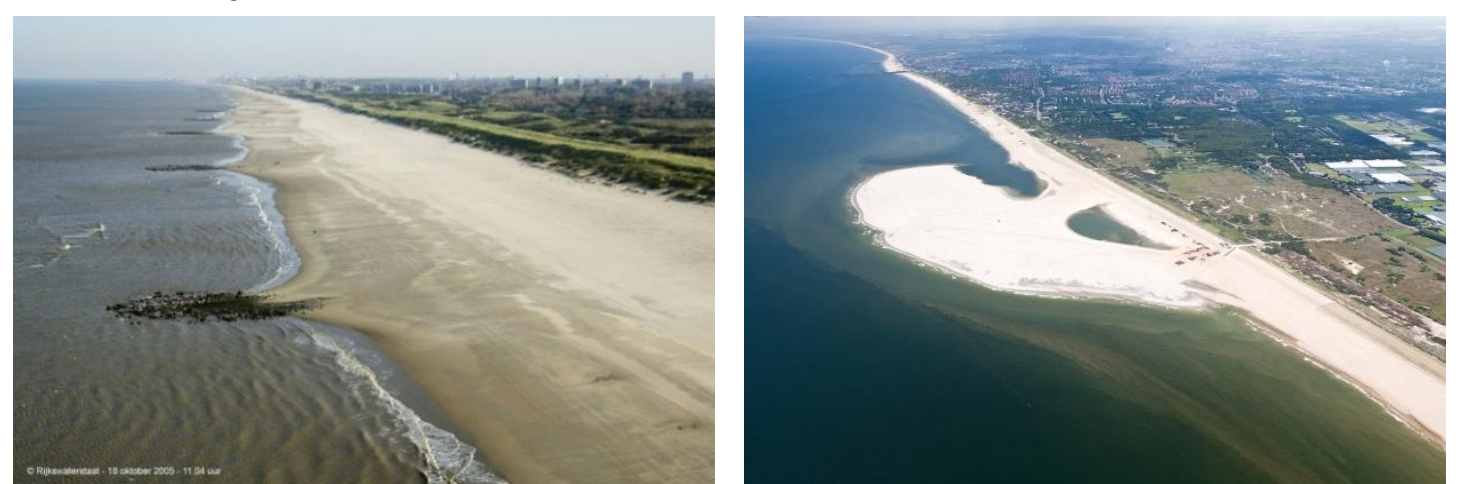

Figure 6 and 7: Coastline between The Hague and Ter Heijde before and after the mega scale nourishment 'The Sandengine'.

\section{METHODOLOGY}

The impact of the nourishments on swimmer safety and currents were examined using three different methods. Firstly, lifeguards at all three field sites were interviewed to gain insight into general swimmer safety issues and, more specific, into which features of beach configuration and nearshore currents and morphology play an important role in swimmer safety. 
Secondly, several years of lifeguard rescue reports were analysed to reveal locations and conditions which had caused problems for swimmers in the past. Records of both nourished and unnourished beaches were analysed. For field site 2, Scheveningen beach, additional regular meetings with the lifeguards were held to monitor the first season post nourishment.

Thirdly, GPS drifters were deployed to measure the current pattern inside and just outside the surf zone for specific conditions, beach configurations and locations (i.e. groynes, rip channels, lateral boundaries of nourishment). To investigate the influence of the topography on the observed current patterns, GPS drifter surveys were often complemented with a bathymetric survey using a Personal WaterCraft (PWC / jetski) based system.

\section{INSTRUMENTS}

\section{Topography measurements, Nearshore Monitoring jetski}

The bottom topography was surveyed just before or after the current measurements using PWC (jetski) surveys. The water depth below the jetski is measured with a Hydrobox Single Beam Echo Sounder (SBES, sounding frequency $10 \mathrm{~Hz}$ ). The position of the jetski (in all three directions) is determined by the Septentrio GPS receiver. An accurate position is calculated by using the Real Time Kinematic (RTK-GPS) technique. The GPS position of the jetski is corrected through correction values obtained through a UMTS connection with a base station. SBES and GPS measurements are logged continuously on an on board laptop with Hypack Hydrographic software. A monitor mounted on the jetski provides real time information to the pilot, such as position, instrument status, sailed survey tracks and planned survey lines. Full description of the survey system is described in Van Son et al. (2009).

Typically, the bottom topography was surveyed using PWC (jetski) surveys around high tide and low wave energy conditions. The sub aqueous surveys were complemented with RTK GPS 4wd- and walking surveys on the sub aerial beach around low tide, giving a full coverage from $-5 \mathrm{~m}$ to $+3 \mathrm{~m}$ above MSL.

\section{Lagrangian current measurements, GPS drifters}

The GPS drifters are free-floating devices used to derive the velocities of the top layer of the watercolumn. The GPS records the position of the drifter with high accuracy enabling to calculate the velocities and to make a coupling of drifter trajectories with the bottom contours. The GPS drifters (Figures 8 to 10) are built similar to the design described by MacMahan et al. (2009). They consist of a buoyant $0.1 \mathrm{~m}$ by $0.3 \mathrm{~m}$ PVC body on which a $0.7 \mathrm{~m}$ by $0.03 \mathrm{~m}$ PVC mast is attached. The GPS antenna is mounted on top of the drifter on a metal disk with a diameter of $0.05 \mathrm{~m}$. Three fins along the shaft of the body are attached for sail area under water. The drifters are designed to minimise surfing back to the beach on the roller of a breaking wave, as they tilt on wave impact. A flat plate attached to the bottom reduces surfing and ballast weights attached to the bottom increase stability of the drifters. The drifters were shown to closely follow simultaneous dye release and passive swimmers.
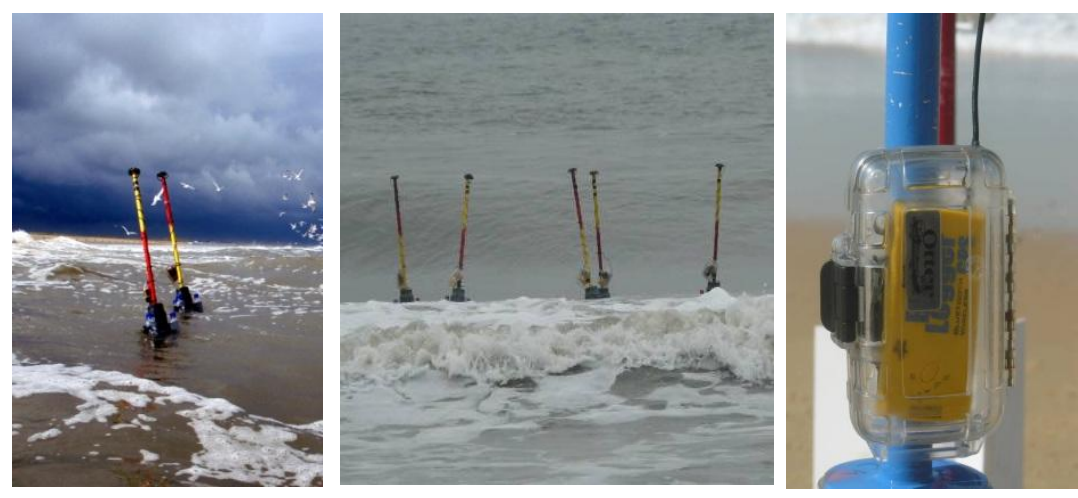

Figures 8, 9 and 10: GPS data loggers attached to PVC buoys. (GPS drifters)

The GPS data loggers are housed in a waterproof box attached to the mast, see Figure 10. The loggers internally record carrier phase information on one frequency at a sampling frequency of $0.5 \mathrm{~Hz}$. The capacity of the loggers allows for measurements up to three hours. Position accuracy is in the order 
of $10 \mathrm{~m}$. But the logger data can be post processed with GPS correction values of a nearby base station. Post processed horizontal position accuracy is in the order of $1 \mathrm{~m}$ and less. Vertical post processed position accuracy is in the order of meters. This is acceptable because the interest lies in accurate horizontal positions.

The advantages of the GPS drifters are their deployment flexibility, low production costs and small weight. Large areas can be covered with relatively little effort. They offer the possibility to visually identify interesting flow patterns during the measurements, such as rip currents (Dalrymple et. al, 2011) or longshore accelerations. Moreover, if one regards swimmers in distress as more or less floating objects subjected to the flow in the upper part of the water column, the drifters can be regarded as a proxy for their trajectory.

\section{OBSERVATIONS FOR GROYNED BEACHES}

\section{General current pattern}

Prior to the nourishments, the typical beach configuration along the South-Holland coast is a groyned beach, see Figure 11. It consists of a row of dunes, a fairly wide upper beach $(\mathrm{O}(100 \mathrm{~m}))$ and a dissipative, mildly sloping inter- and sub tidal beach face $(1: 50-1: 100)$. The groynes are separated $250-500 \mathrm{~m}$ in alongshore direction, are 100-200 $\mathrm{m}$ long with crest levels around MSL. The predictable morphology (in space and time) in between the groynes is gently sloping in both along and cross shore direction. Often one or two bars are present between the groynes, incised with a shallow rip channel $(\mathrm{O}(10-50 \mathrm{~cm})$ relative to the bar top) and a deep channel adjacent to the groynes (Fig 12.). The predictable character of the morphology in between the groynes was perceived to be beneficial to swimmer safety by the lifeguards.

Due to the characteristic predictable morphology, the nearshore current pattern was also predictable and well-known amongst lifeguards (due to decades of experience). The groynes with a crest level at approximately MSL deflect wave and tidal alongshore currents in the low tide period and invoke a strong outward flowing current. The current pattern on a beach with emerged groynes shows permanent rips at the upstream side of the groyne due to any longshore current and possibly eddies in the lee side of the groynes, see Fig. 13. The reduced longshore current in between the groynes (indicated as A in Fig. 13) compared to offshore (B, Fig 13) is perceived as a positive effect of the groynes on swimmer safety. On the other hand, the deflected offshore flowing current along the sides of the groynes poses a hazard for swimmers and therefore a negative effect on swimmer safety.

Besides rip currents invoked by alongshore currents, near shore-normal wave breaking can also induce rip currents in between the groynes. The associated current pattern due to normal incident wave breaking over the (submerged) bar is schematically indicated in Figure 14. In case of normally incident waves there is some wave breaking directly on top of the groyne, almost no wave breaking in the deep areas next to the groyne and intense wave breaking over the submerged bar(s). The set up in water level increases with increasing wave breaking. Consequently, there is a gradient in water level between the area behind the bar(s) and channels. This causes a current towards the channel: the feeder current. The rip currents are stronger with increasing wave breaking over the bar. Besides the gradient in water level, mass flux by and breaking of waves causes a net onshore directed flow over the bar, which flows back offshore through the feeder en rip current channel, enhancing the rip circulation. Generally, a combination of both current patterns will develop, depending on the conditions. 


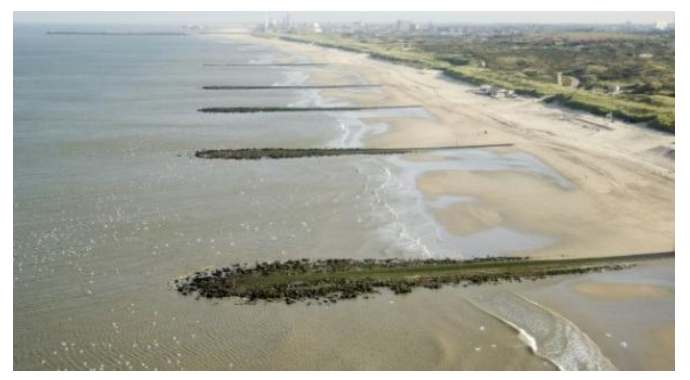

Figure 11: Picture of groynes beach around low tide. (source: www.kustfoto.nl)

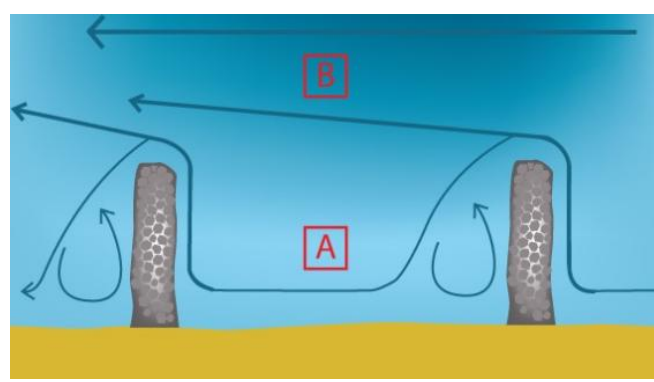

Figure 13: Schematised current pattern under oblique wave incidence or a tidal longshore current. Rip currents on the upstream side, possible eddies in the lee side of the groynes. The thickness of the lines indicates the relative current velocity and the reduction of the longshore current due to the groynes.

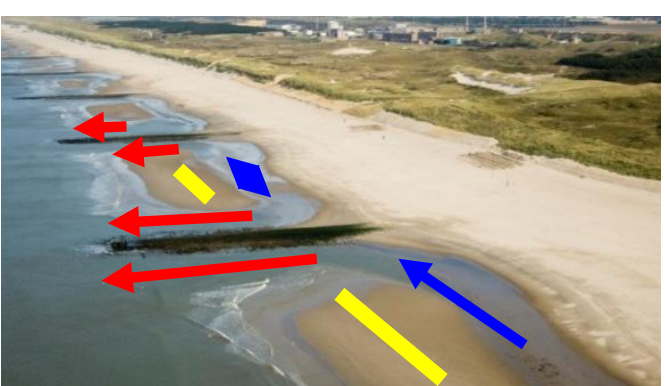

Figure 12: Schematic of permanent rips (red arrows) next to groynes. Breaker bars (yellow lines) and trough/feeder current (blue arrows) are clearly visible in the intertidal bathymetry. (source: www.kustfoto.nl)

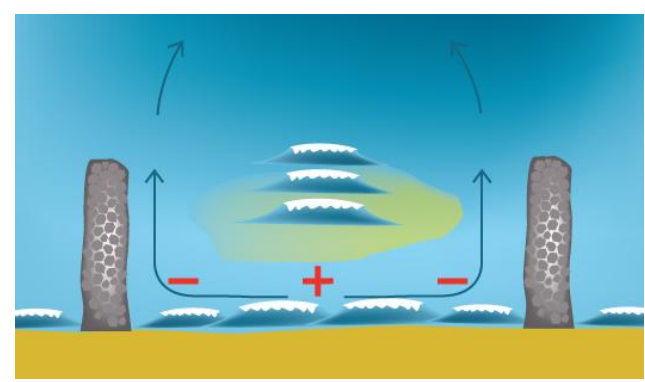

Figure 14: Schematised current pattern under normally incident waves. Shallow submerged bar in between groynes results in water level setup gradients at the shoreline indicated by + and - signs. 


\section{Lifeguard statistics}

Interviews with lifeguards and statistics of the rescue reports revealed that rips near emerged groynes form the biggest threat to swimmers. Figure 15 shows the amount of rescues performed near groynes and on open (nourished) beaches. Figure 16 shows the amount of rescues plotted against wind directions (and tidal phase (both vertical and horizontal tide). The beaches are facing NW, so clearly the majority of the problems for swimmers are related to longshore current invoked rip currents along the emerged groynes. A smaller part of the rescues is related to shore-normal wave breaking and thus rip currents in conventional sense. Amongst others, Lushine (1991) and Lascody (1998) performed similar research in the US to reveal a higher risk on rips for shore-normal conditions.

Injury on impact with the (only just) submerged groynes due to a longshore current is also an issue on these beaches.

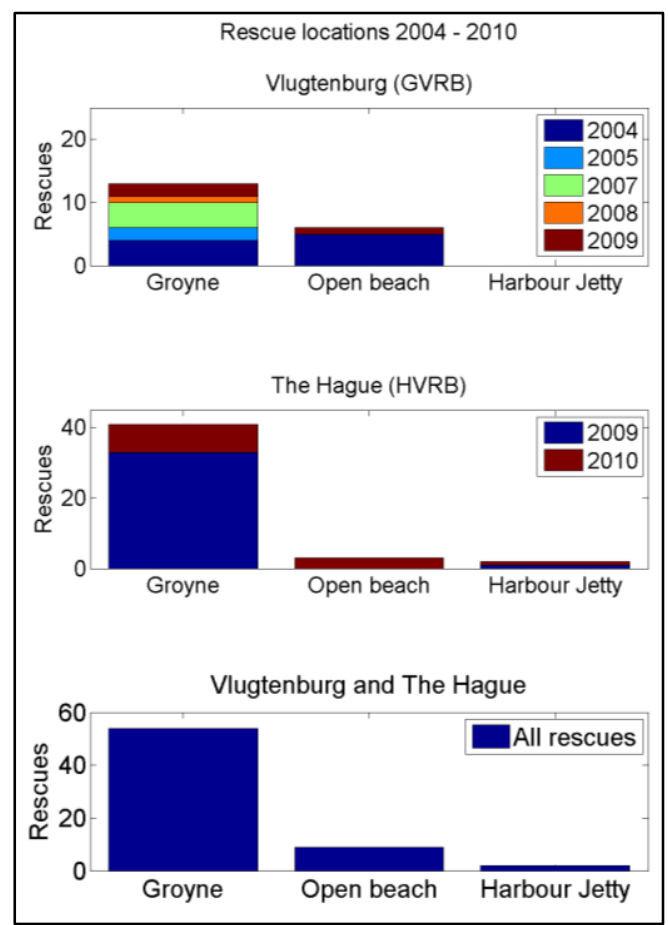

Figure 15: Rescue reports sorted to the location of the rescues, categorized as near groyne, open beach and harbour jetty for the years $2004-2010$ at Vlugtenburg site (top), Scheveningen site (middle) and both sites combined (bottom).

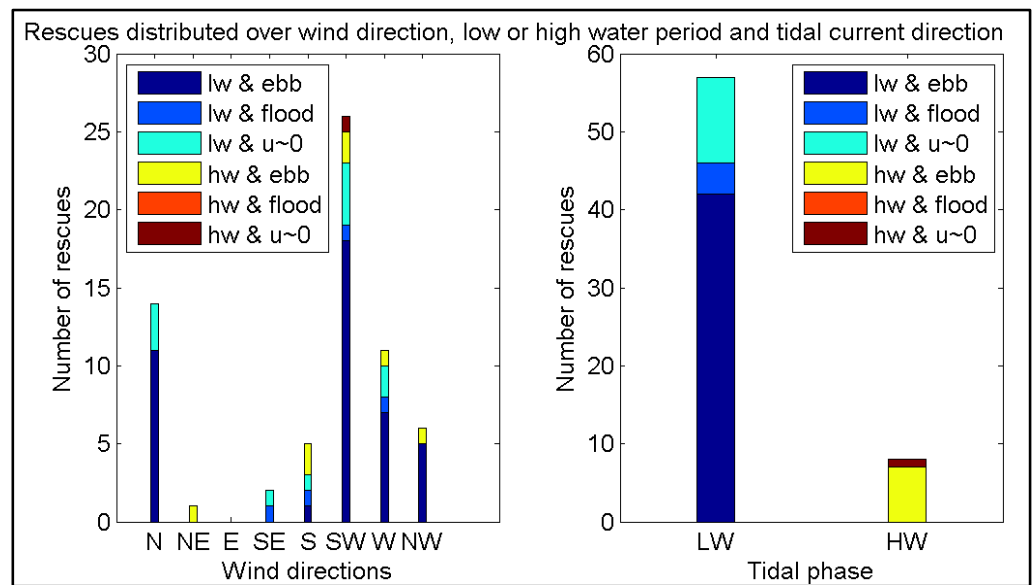

Figure 16: Rescue reports sorted to meteorological conditions and the tidal phase. Left: Rescues distributed over wind direction at times of the rescue. The colours of the bars indicate water level and approximate tidal current direction. Right: Low tide or high tide period at times of rescues.

For more detail on the lifeguards rescues and their relation to wind, wave and tidal conditions the reader is referred to De Zeeuw, 2011. 


\section{GPS drifter observations}

Current measurements on the groyned beaches confirm the existence of rip currents along the sides of emerged groynes for any longshore current. Figure 17 shows one of the measurements performed for obliquely incident waves $\left(\mathrm{H}_{\mathrm{s}}=0.8 \mathrm{~m}, \mathrm{~T}=4.3 \mathrm{~s}\right.$, Dir NNE, $\mathrm{U}_{\text {wind }}=5.3 \mathrm{~m} / \mathrm{s}$ Dir. NNE) at Scheveningen beach. The measured velocities in the rip current are roughly twice as high as the average alongshore (wave driven) current. The measurements also confirm a stronger tidal alongshore current beyond the tip of the groynes. The GPS drifters caught in the rip current are advected by the tidal alongshore current beyond the tip of the groyne. Velocities can be read from the colorbar which corresponds to the colors of the drifter trajectories in the figure.

When the direction of the wave and tidal driven alongshore current coincide the rip current extends $O(20 \mathrm{~m})$ offshore and GPS drifters stay closer to the tip of the groyne and beach. On the contrary, for opposing wave and tidal driven alongshore current direction rip currents extend further offshore, $O$ $(100 \mathrm{~m})$, which is an important result of the measurements and practical swimmer safety management.

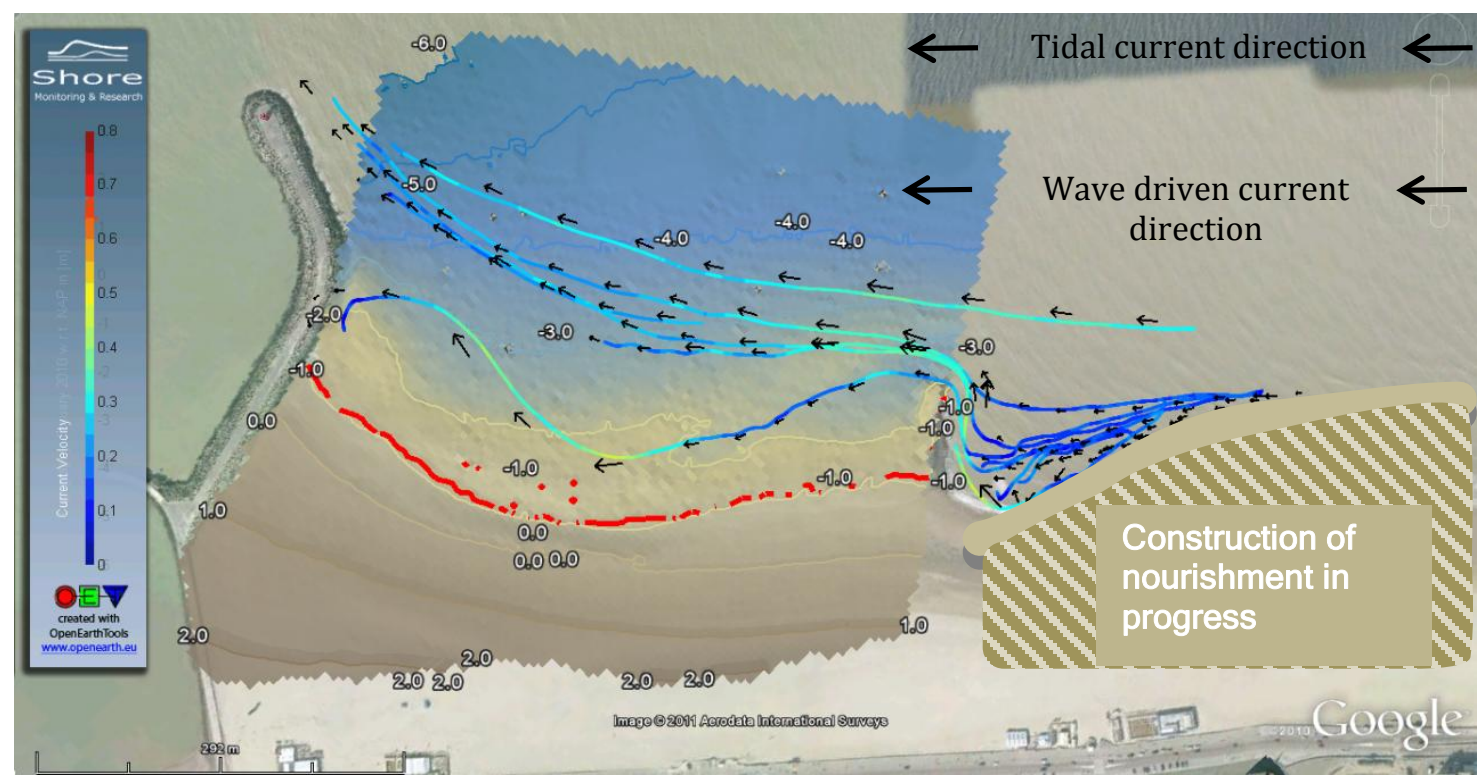

Figure 17: Drifter trajectories near a groyne at Scheveningen. Paths show the drifter trajectories, colors herein correspond to the velocity $(\mathrm{m} / \mathrm{s})$ as indicated by left colorbar, black arrows indicate direction. Blue/grey shading and contours indicate bottom elevation in $\mathrm{m}$ NAP. Beige shaded thick line indicates approximate waterline due to commenced construction of the nourishment.

\section{OBSERVATIONS FOR NOURISHED BEACHES}

This section presents the main observations on nourished beaches. Results situation prenourishment discussed in the previous section are used to reflect on the changes due to the nourishment.

\section{GPS drifter observations}

Measurements on the open nourished beach (area indicated by dotted black arrow in Figure 18) revealed strong alongshore currents close to the waterline for most measurements and no rip currents for obliquely incident waves, see Fig. 18. This is almost the opposite situation compared to the groyned beach. The strong longshore current close to the waterline could be explained by the steep beach profile post nourishment, see Fig. 19, and the absence of groynes. 


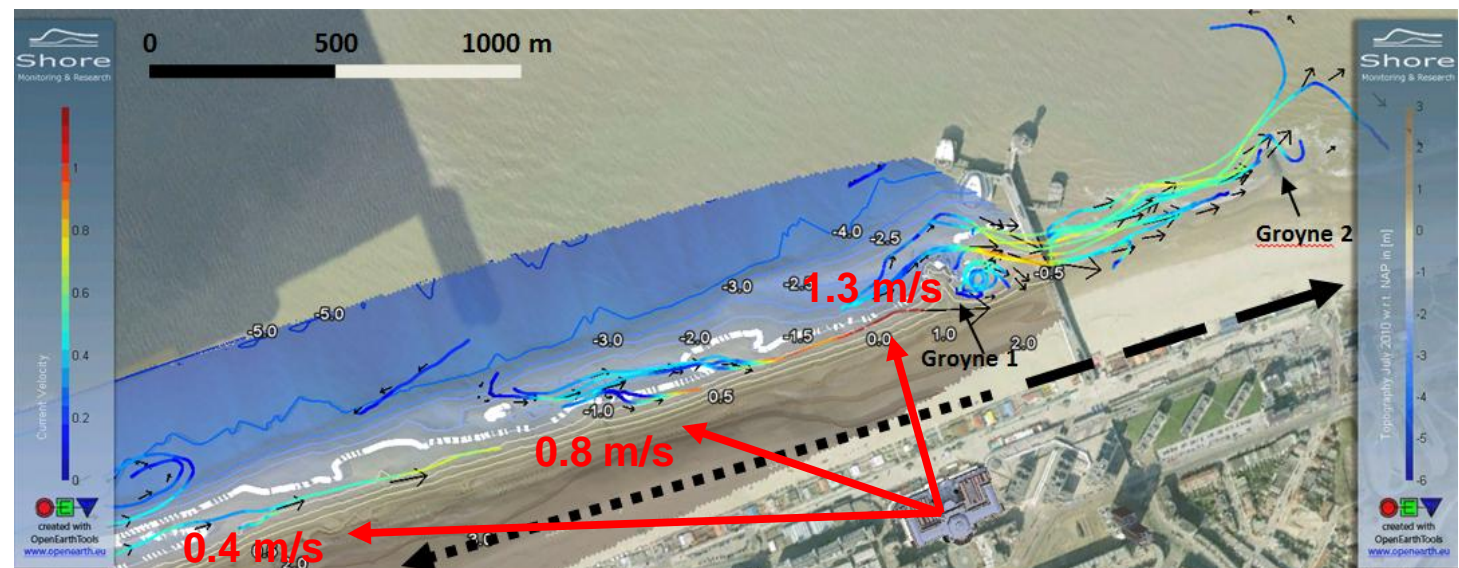

Figure 18: GPS Drifter tracks as measured at Scheveningen $\left(H_{s}=1.65 \mathrm{~m}, T=5.0 \mathrm{~s}, \mathrm{Dir}=\mathrm{SW}, \mathrm{U}_{\text {wind }}=9 \mathrm{~m} / \mathrm{s}\right.$, Dir = SW, ebb tidal current), for a nourished (dotted line) and groyned beach (dashed line). Paths show the drifter trajectories, colors herein correspond to the velocity $(\mathrm{m} / \mathrm{s})$ as indicated by left colorbar, black arrows indicate direction. Grey/blue color shading and contours show bathymetry $(\mathrm{m})$ with respect to NAP as indicated by right colorbar. Nourished section of the beach shows strong longshore currents. The unnourished part is characterised by rips (groyne 2) and eddies (groyne 1). White dotted line shows the approximate breakerline.

To illustrate the big difference between the current pattern between the two beach configurations Figure 7 also shows the current pattern near the groynes outside the nourishment area (area indicated by dashed black arrow in Figure 7). It clearly shows the offshore invoked rip currents at groyne 2 (notice the offshore extent of the rip due to opposing wave and tidal driven current). In the lee of groyne 1 an eddy was measured with offshore velocities larger than $0.4 \mathrm{~m} / \mathrm{s}$.

The conditions that caused the majority of the rip currents on the groyned beach don't cause rip currents on the nourished beach. Rip currents on the nourished beach were only observed for nearshore-normal incident waves combined with bottom variations with in the surf zone. However, velocities in these rip currents were generally weaker than the tidal current outside the surf zone, and overall weaker than the rip currents measured near groynes.

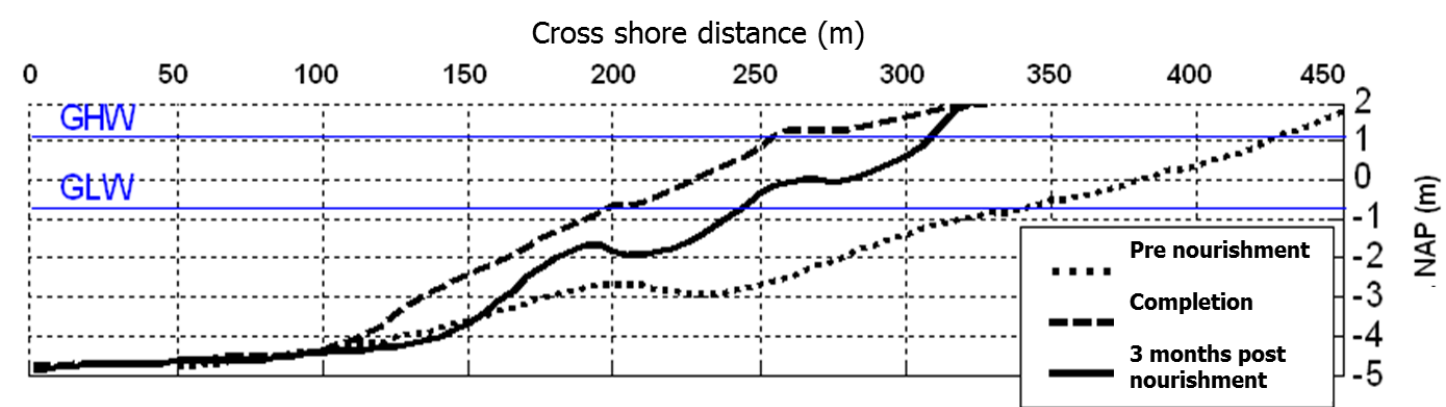

Figure 19: A beach profile at Scheveningen pre-nourishment (dotted), at completion of the nourishment (dashed) and 3 months post-nourishment (solid).

\section{Lifeguard observations of swimmer safety.}

Interviews with the lifeguards revealed one of the major issues of the lifeguards on the nourished beach is the unpredictability (in time and space) of the nearshore morphology and occurrence of rip currents. Despite the fact that most rescues on the groyned beach had to be performed near the groynes, the lifeguards felt in control of the situation. For an import part due to their experience (decades) with the groynes. On the nourished beach past experience isn't applicable anymore, leading to uncertainty.

After construction of the nourishments steep profiles were observed, causing shorter, stronger surf close to the beach. At many locations scarps formed. Figure 20a illustrates the hazardous nature of the strong surf and steep profile for bathers. Besides the hazard to swimmers, the scarps also blocked their view on the waterline from their observation stations.

Generally an alongshore (oblique) trough and bar system developed, see also Fig. 19. Combined with a strong longshore current, several hazardous situations were reported. Bathers were drawn to the 
bar at low tide to which they, in that tidal phase, could wade. With rising tide the alongshore current increases and the trough becomes too deep to wade through, forcing people to swim back to the beach and at the same time drifting alongshore, see Fig. 20b. At some locations the through was orientated obliquely offshore forming a very hazardous situation, see Fig 20c.

The shallow subtidal bar also limited their possibilities to patrol the nearshore by boat. Launching the boat at low tide only permitted them to sail in the trough, because the bar was too shallow to cross with the boat.

The lateral boundaries of nourishments often introduce gradients in the coastline. The smoother these gradients are, the less the local hydrodynamics and morphology differ from the rest of the beach. However, these gradients are often clearly visible and not very smooth. At these gradients accelerations of the longshore wave driven current and variations in beach profiles are observed, see Fig. 21.

When wave angle of incidence and the shore-normal at the gradient are parallel rip currents can also form. The lifeguards of Vlugtenburg have reported serious incidents with swimmers at similar locations as shown in Figure 21.

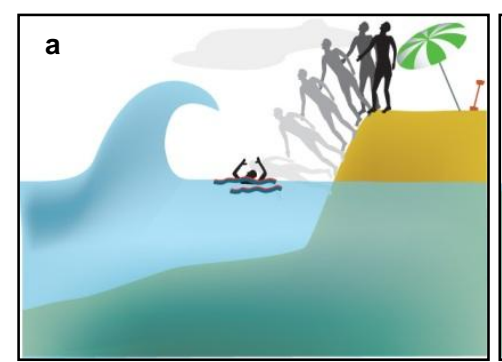

Figure 20: Schematics of hazardous situations after installation of the nourishment. a) Steep profile and stronger surf close to waterline, b) Shallow bar and deep trough combined with rising tide, c) Oblique trough and longshore current.
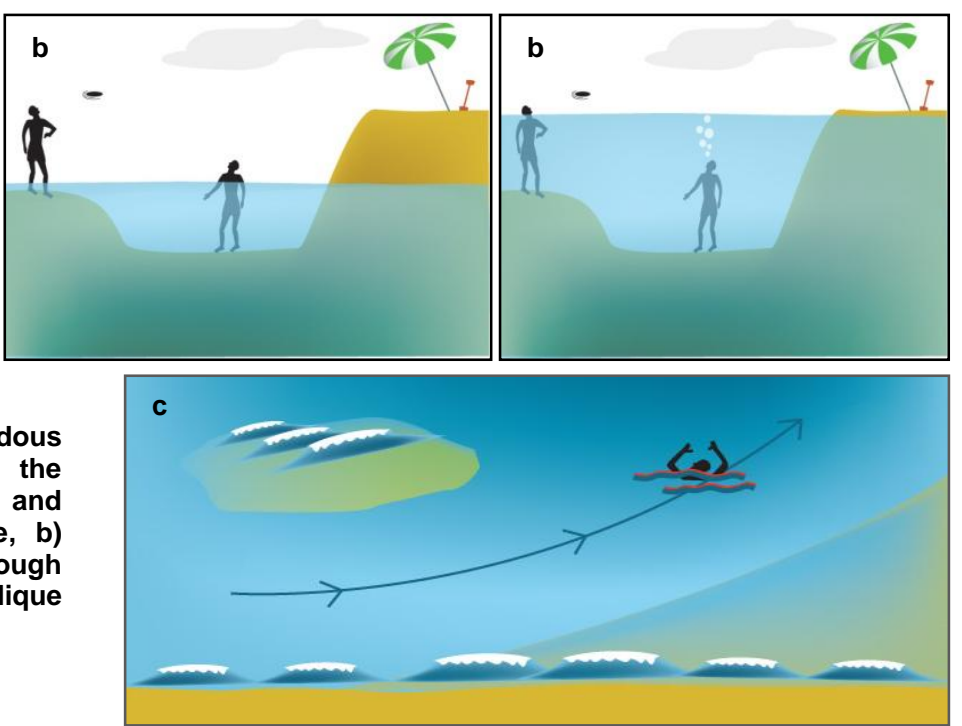

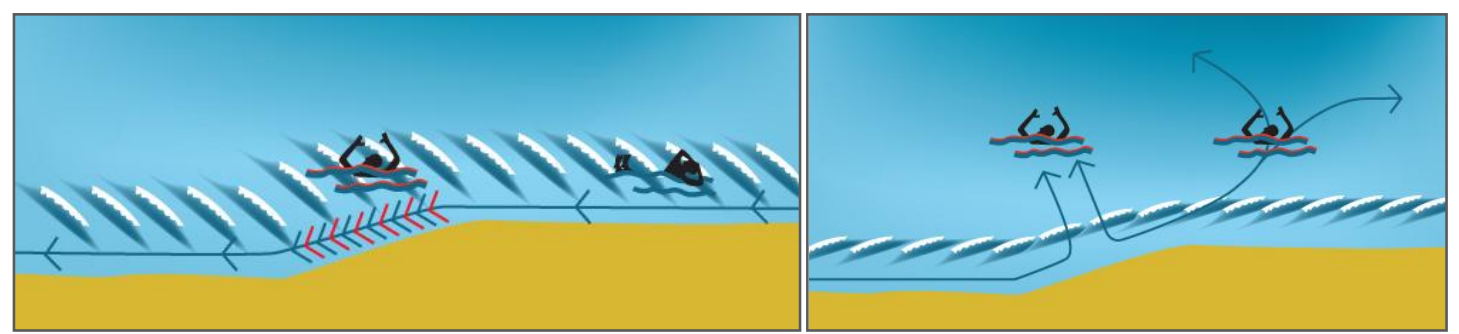

Figure 21: Schematics of hazardous situations near the lateral boundaries of the nourishment. Alongshore coastline gradients can cause alongshore flow acceleration (left) or rip currents depending on wave direction and shoreline orientation.

\section{Mega nourishment the Sand engine}

Observations at the mega scale nourishment, the Sand engine peninsula highlights the danger of gradients in the coastline (Fig. 22). As the nourishment protrudes far from the surrounding coastline, the alongshore gradients in the coastline in combination with an alongshore current are clearly important in the assessment of the local swimmer safety here. Bathers caught in the alongshore current risk being transported alongshore at $1 \mathrm{~m} / \mathrm{s}$ finding themselves more than $1500 \mathrm{~m}$ removed from the closest coastline. In the GPS drifter experiment shown in Fig 22, wave, wind and tidal driven current all acted in northeast alongshore direction, amplifying the danger for ocean bathers.

Note that at the SW facing flank of the Sand engine peninsula the waves were near shore-normal incident and while alongshore currents are small, clear rip currents were observed. 


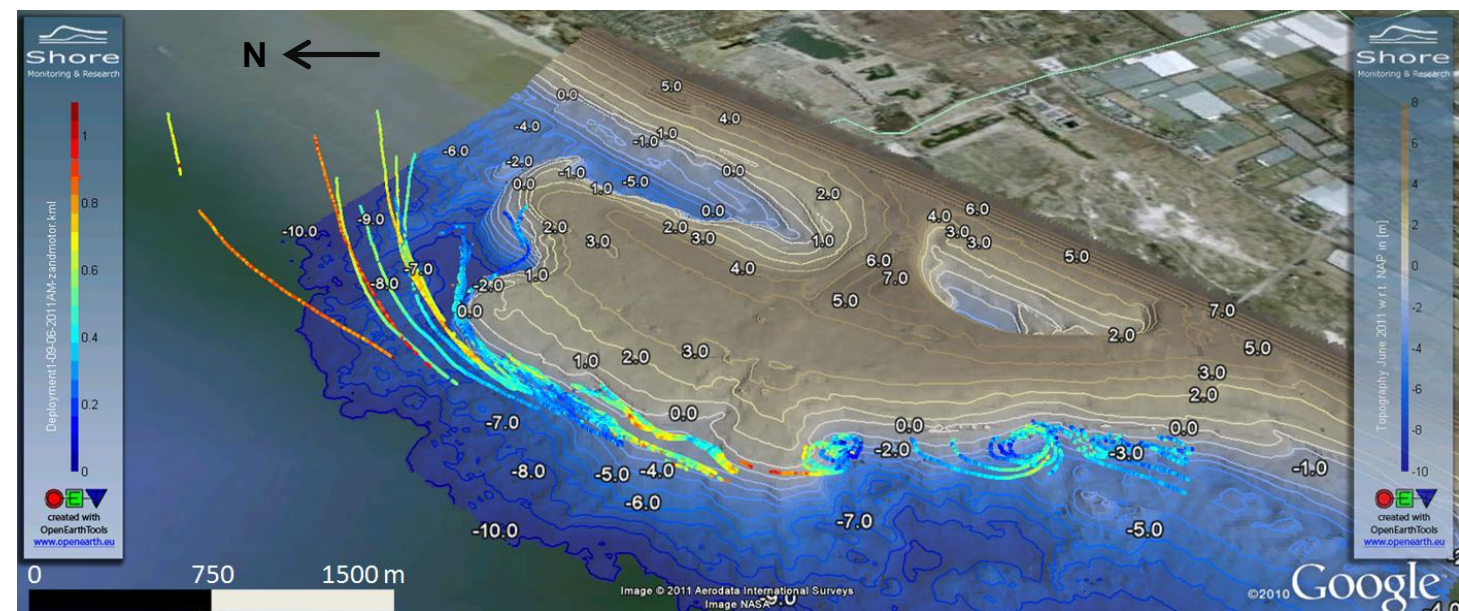

Figure 22. GPS Drifter tracks as measured at the Sand engine. Paths show the drifter trajectories, colors herein correspond to the velocity $(\mathrm{m} / \mathrm{s})$ as indicated by left colorbar, black arrows indicate direction. Grey/blue color shading and contours show bathymetry $(\mathrm{m})$ with respect to NAP as indicated by right colorbar.

\section{CONCLUSION}

After studying swimmer safety at three field sites along the South-Holland coast, using lifeguards interviews, rescue report statistics, detailed GPS drifter current measurements and surveys of the bottom topography seven criteria are formulated to assess swimmer safety along the Dutch coast:

- Bars, troughs and channels

- Profile gradients

- Coastal structures

- Rip currents

- Predictability

- Longshore currents

- Coastline gradients

\section{ACKNOWLEDGMENTS}

Various lifeguard stations along the South Holland coast are greatly acknowledged for providing the rescue reports and cooperating with the surveys. The municipality of the Hague is acknowledged for supporting the research at Scheveningen beach. Field observations with GPS drifters were obtained with the help of many volunteers, often students from UNESCO-IHE. Their voluntary help was much appreciated.

M.A. de Schipper and S. de Vries are funded by Ecoshape/Building with Nature under Project Code NTW 3.2 and HK 2.1 respectively. The Building with Nature program is funded from several sources, including the Subsidieregeling Innovatieketen Water (SIW, Staatscourant nrs 953 and 17009) sponsored by the Dutch Ministry of Transport, Public Works and Water Management and partner contributions of the participants to the Foundation EcoShape. The program receives co-funding from the European Fund for Regional Development EFRO and the Municipality of Dordrecht. M. Stive is partly supported by the European Research Council under the European Community's Seventh Framework Programme (FP7/2007-2013) / ERC Grant agreement n ${ }^{\circ} 291206$ ]-NEMO.

\section{REFERENCES}

Dalrymple, R.A., MacMahan, J., Reniers, A.J.H.M. \& Nelko, V. 2011. Rip Currents. Ann. Rev. of Fluid Mechanics, 43, $551-581$

Lascody, R.L.., 1998. East central Florida rip current program. National Weather Digest 22, 25-30

Lushine, J.B., 1991. A Study of Rip Current Drownings and Related Weather Factors. National Weather Digest, 16, 13-1

MacMahan, J., Brown, J. \& Thornton, E. 2009. Low-Cost Handheld Global Positioning System for Measuring Surf-Zone Currents. Journal of Coastal Research, 744-754 
Son, S.T.J. van, Lindenbergh R., Schipper, M.A. de, Vries, S. de and Duijnmayer, K. 2009. Using a personal watercraft for monitoring bathymetric changes at storm scale. Proceedings of the International Hydrographic Conference.

Zeeuw, R.C. de, 2011, Nearshore currents and swimmer safety in the Netherlands, MSc. Thesis. 